\section{Delayed response performance by rhesus monkeys with midprincipalis lesions*}

\author{
J. M. WARREN and IVAN DIVAC $†$ \\ The Pennsylvania State University, University Park, Pa. 16802
}

Four rhesus monkeys were trained on delayed response in the WGTA and subjected to lesions of the middle third of sulcus principalis. Two monkeys were very severely impaired in postoperative retention tests; two Ss manifested milder deficits in postoperative performance. It was concluded that the middle third of sulcus principalis is important for the mediation of delayed response as well as delayed alternation and that the two tasks probably are equivalent measures of the same supramodal learning process.

The success that has attended recent efforts to partition the frontal granular cortex in monkeys on anatomical (Jones \& Powell, 1970; Nauta, 1971 Pandya, Dye, \& Butters, 1971) and behavioral grounds (Goldman, Rosvold, \& Mishkin, 1970; Gross \& Weiskrantz, 1962; Mishkin, Vest, Waxler, \& Rosvold, 1969; Stepien \& Stamm, 1970) raises the possibility that the conventional assumption that delayed response (DR) and delayed alternation (DA) are equivalent measures of the same impairment is invalid.

Three kinds of evidence suggest that $D A$ and DR could be mediated by different neural systems. (1) Intact infant macaques do not attain adult levels of proficiency on DA as soon as on DR (Goldman, 1971; Goldman \& Rosvold, 1970; Kling \& Tucker, 1968). (2) Monkeys subjected to prefrontal decortication in infancy are more severely impaired on DA than on DR (Goldman \& Rosevold, 1970; Kling \& Tucker, 1968). (3) Lesions in the cingulate gyrus or in temporal lobe structures cause greater loss on DA than on DR (Mâhut, 1971; Pribram, Wilson, \& Connors, 1962; Rosvold \& Szwarcbart, 1964).

Ablations involving only the middle third of sulcus principalis result in a profound impairment of DA retention by monkeys (Butters \& Pandya, 1969; Butters, Pandya, Sanders, \& Dye, 1971). The purpose of this experiment was to determine if the same area was also important for the retention of $D R$ by adult rhesus monkeys, in order to test the hypothesis that DA and DR retention are mediated by separable neural mechanisms in monkeys. SUBJECTS

Four experimentally sophisticated rhesus monkeys with extensive and

* This research was supported by Grant MH 04726 from the National Institute of Mental Health, U.S. Public Henlth Service.

+ Now at the Institute of Neurophysiology, University of Copenhagen, Copenhagen, Denmark. identical histories of training on discrimination and reversal problems served in this experiment. All of the animals had been trained for 500 trials on DR with $0-, 5-$, and 10-sec delays 1 month before starting the present experiment.

\section{APPARATUS AND STIMULI}

Testing was carried out in the Wisconsin General Test Apparatus (WGTA), illustrated in Harlow (1949). The manipulanda were two identical orange plastic cups, $9 \mathrm{~cm}$ high and
$7 \mathrm{~cm}$ in diam, presented on a white test tray containing two foodwells, spaced $30 \mathrm{~cm}$ apart.

\section{PROCEDURE}

A. trial began with the opaque screen lowered in front of the monkey. E positioned the cups $3 \mathrm{~cm}$ behind the foodwells, raised the opaque screen, and displayed a peanut, raisin, or small piece of apple until $\mathbf{S}$ reached for the food or visually fixated it. $E$ next placed the incentive in the predetermined correct foodwell, covered both wells with the cups, and lowered the one-way vision screen (except on trials with 0 -sec delays). At the end of the delay, $E$ pushed the tray forward and permitted the monkey to displace a single cup. The tray was then withdrawn, and the opaque screen was lowered in front of $S$ to end the trial. Note that the monkey could see the cups throughout the delay period, since the opaque screen was used only between trials.

Each 25-trial session consisted of blocks of 5 trials with 0 -sec delays, 10 trials with 5 -sec delays, and 10 trials with 10-sec delays. The 0 -sec trials were always presented at the start of the session, but the order in which 5 .

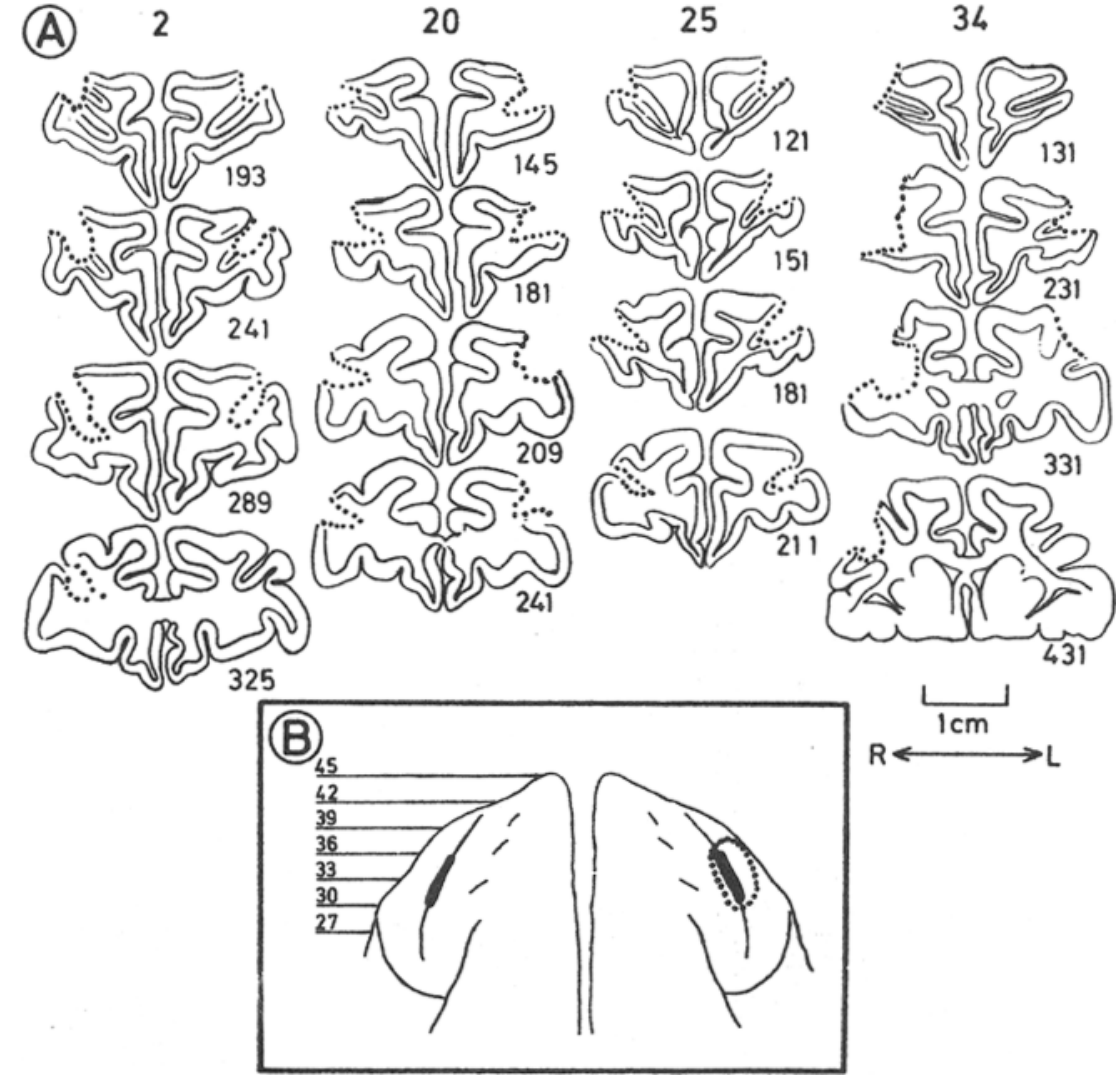

Fig. 1. (A) Cross sections illustrating the lesion at approximately its rostral and caudal limits and at one-third and two-thirds of its extent in the four monkeys. (B) Schematic representation of the lesion in all four monkeys; dots indicate the zone of softening in Monkey 34. 


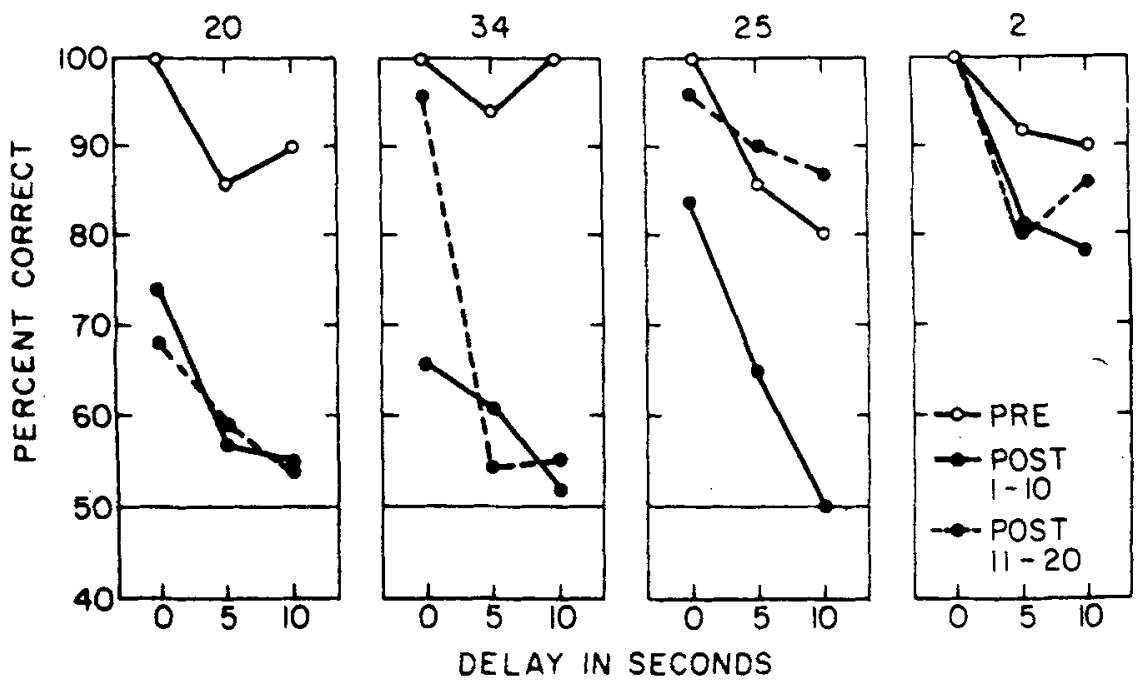

Fig. 2. Delayed response performance as a function of length of delay in preand postoperative training.

and 10 -sec delay trials were given was varied over days in an ABBA sequence.

The monkeys were retested on $D R$ for 10 days, operated, and allowed to recover for 2 weeks, and then tested for 20 days postoperatively. Since the monkeys were tested by an $\mathrm{E}$ who was at first unfamiliar with the animals' food preferences, their initial performance on the preoperative retention test was somewhat erratic. The preoperative scores are consequently given as the mean percentage of correct responses on the last 5 days of preoperative testing.

\section{SURGERY}

The monkeys were anesthetized with $36 \mathrm{mg} / \mathrm{kg}$ of pentobarbital injected intraheptically. The banks and depth of the middle third of sulcus principalis were ablated bilaterally by gentle subpial aspiration under aseptic conditions.

\section{HISTOLOGY}

The Ss were deeply anesthetized and perfused transcardially with saline followed by $10 \%$ neutral formalin in saline. The brains were removed, photographed, hardened in Formalin, and embedded in celloidin before being cut in 40-micron sections. Every 10 th or 12th section through the cortical lesion and every 5 th section through the thalamus was stained with cresyl violet.

\section{RESULTS \\ Anatomy}

Representative cross sections through the lesions in the four monkeys and a reconstruction showing the locus and extent of the cortical ablaticns in these Ss on a dorsal view of the monkey's brain are presented in Fig. 1. The lesion in Monkey 20 closely approximated the surgeon's intentions. The right frontal region in Monkey 34 showed softening, probably as a result of local circulatory impairment. The depth of the rostral part of the middle third of the principal sulcus was spared bilaterally in Cases 2 and 25 . Microscopic examination of the thalamus revealed zones of gliosis and cell loss in the parvocellular portion of mediodorsal nucleus which was proportional in size to the extent of the cortical insults.

\section{Behavior}

The significance of changes in the group's performance on DR was assessed by $t$ tests for related measures, which indicate that the mean percentage of correct responses on 5 -sec $(t=4.94)$ and 10 -sec $(t=4.19)$ delays was significantly lower during the first 10 postoperative days than preoperatively.

The individual performance curves given in Fig. 2, where percent correct responses is plotted as a function of length of delay with test periods as the parameter, show a wide range of responses to the lesions. Monkey 20 was severely impaired; chi-square tests indicate that its scores at all delays and on both blocks of postoperative trials did not deviate significantly from chance. Monkey 34 was also seriously disturbed and achieved significantly better than chance scores only on 0 -sec delays on Postoperitive Days 11 through 20. Monkey 25 responded at chance levels on $5-$ and 10 -sec delays during the first 10 postoperative days but regained preoperative levels of proficiency with continued training. Monkey 2 made significantly better than chance scores throughout postoperative testing but was consistently less competent on 5- and 10 -sec delays than he had been preoperatively.

\section{DISCUSSION}

The monkeys observed in this experiment were significantly impaired in $\mathrm{DR}$ performance after lesions in the middle third of sulcus principalis, and two of four were severely impaired throughout the postoperative period. These results are rather impressive because the DR task used in the present study was not a particularly demanding one. The monkeys could see the stimuli during the delay period, and each session began with a set of 0 -sec delays.

The fact that only two of four monkeys showed a prolonged and severe deficit in DR performance cannot be construed as evidence that the midprincipalis area is less important for the mediation of DR than for that of DA. Several investigators have found that some monkeys with essentially complete ablations of the principal sulcus can perform adequately on postoperative DA tests (Gross, 1963; Mishkin, 1957; Rosen, Stein, \& Butters, 1971, Stamm \& Weber-Levine, 1971). Principalis lesions do not abolish either DA or DR capability as consistently as larger lateral frontal lesions (Gross, 1963; Stamm \& Weber-Levine, 1971).

In view of these considerations, we must conclude that this investigation yielded no support for the speculation that DR and DA depend upon the integrity of different foci within the frontal granular cortex in monkeys. Indeed, the present results tend to strengthen rather than to weaken the view that $D R$ and $D A$ are largely equivalent behavioral measures of the same neural activity in the prefrontal cortex. Our data unfortunately do not illuminate the problem of why medial temporal lesions affect DA but not DR performance (Mahut, 1971).

\section{REFERENCES}

BUTTERS, N., \& PANDYA. D. Retention of delayed-alternation: Effect of selective lesions of sulcus principalis. Science. $1969,165,1271-1273$.

BUTTERS, N., PANDYA, D., SANDERS, K., \& DYE, P. Behavioral deficits in monkeys after selective lesions within the middle third of sulcus principalis. Journal of Comparative \& Physiological Psychology, 1971, 76, 8-14.

GOLDMAN, P. S. Functional development of the prefrontal cortex in early life and the problem of neuronal plasticity. Experimental Neurology, 1971, 32 Exp erim

GOLDMAN, P. S., \& ROSVOLD, H. E. Localization of function within the dorsolateral prefrontal cortex of the rhesus monkey. Experimental Neurology, $1970,27,291-304$.

GOLDMAN, P. S., ROSVOLD. H. E., \& MISHKIN, M. Selective sparing of function following prefrontal lobectomy in infant monkeys. Experimenta Neurology, 1970, 29, 221-226.

GROSS, C. G. A comparison of the effects of partial and total lateral frontal lesions on test performance by monkeys. Journal of Comparative \& Physiological Psychology, 1963, 56, 41-47.

GROSS, C. G.. \& WEISKRANTZ, L. Evidence for dissociation of impairment on auditory discrimination and delayed response following lateral frontal lesions 
in monkeys. Experimental Neurology, $1962,4,453-476$.

HARLOW, H. F. The formation of learning sets. Psychological Review, 1949, 56, 51-65.

JONES, E. G., \& POWELL. T. P. S. An anatomical study of converging sensory pathways within the cerebral cortex of the monkey. Brain, 1970, 93, 793-820.

KLING, A., \& TUCKER, T. J. Sparing of function following localized brain lesions in neonatal monkeys. In R. L. Isaacson (Ed.), The neuropsychology of development. New York: Wiley, 1968. Pp. 121-145.

MAHUT, H. Spatial and object reversa learning in monkeys with partial tempora lobe ablations. Neuropsychologia, 1971. 9, 409-424.

MISHKIN, M. Effects of small frontal lesions on delayed alternation in monkeys. Journal of Neurophysiology, $1957,20,615-622$.

MISHKIN, W., VEST, B., WAXLER, M., \& ROSVOLD, H. E. A re-examination of the effects of frontal lesions on object alternation. Neuropsychologia, 1969,7, 357-363.

NAUTA. W. J. $H$. The problem of the frontal lobe: A reinterpretation. Journal of Psychiatric Research, 1971, 8, 167-187.

PANDYA. D.. DYE, P., \& BUTTERS, N. Efferent cortico-cortical projections of the prefrontal cortex in the rhesus monkey, Brain Research, 1971, 31 , 35-46.

PRIBRAM, K. H., WILSON, W. A., \& CONNORS, J. Effects of lesions of the medial forebrain on alternation behavior of rbesus monkeys. Experimental Neurology, 1962, 6, 36-47.
ROSEN, J., STEIN, D., \& BUTTERS, N. Recovery of function after serial ablation of prefrontal cortex in the rhesus monkey. Science, 1971, 173, 353-356.

ROSVOLD, H. E., \& SZWARCBART, M. K. Neural structures involved in delayed-response performance. In $J$. $M$. Warren and $\mathrm{K}$. Akert (Eds.), The frontal granular cortex and behavior. New York: McGraw-Hill, 1964. Pp. 1-15

STAMM, J. S., \& WEBER-LEVINE, M. L. Delayed alternation impairments following selective prefrontal cortical ablations in monkeys. Experimental Neurology, 1971, 33, 263-278.

STEPIEN, I., \& STAMM, J. S. Impairments on locomotor task involving spatial opposition between cue and reward in frontally ablated monkeys. Acta Neurobiologiae Experimentalis (Warsaw). 1970, 30, 1-12. 